collision, which seemed almost inevitable, with the roof of the "Glastonbury Kitchen." Directly after the seizure of the butterfly, Mr. Holland saw the wings fluttering to the ground, evidently cut through at their bases by the beak.-E. B. P.

I CAN corroborate tne statement that the house-sparrow frequently pursues and captures the large white cabbage butterfly.

Probably the kestrel preys extensively on the emperor moth, whose wings I have seen lying at the base of the small hum. mocks formed by the Juncus squarrosus on the Orkney moorlands. These tufts were much used as resting places by kestrels and hen harriers, but as neither hawk is capable of catching a bird on the wing, the moths were presumably captured while at rest.

The black-headed gull feeds on the common ghost moth Regularly every season, during many years, I saw some half dozen or more of these gulls flying backwards and forwards, about three feet above the ground, over the grass in front of my house, hawking after the white oscillating ghost moths in the long summer twilight of a calm Orcadian evening.

7, Bon Accord Square, Aberdeen, February 3.

$$
\text { W. IRvine For'tescue. }
$$

\section{The Severn Bore.}

IN NATURE of January 23 there is an interesting illustration of the Severn Bore, as photographed by Dr. Vaughan Cornish. If I understand the note rightly, the bore took a little more than a minute to travel 500 yards, and this gives a rate of almost exactly seventeen miles an hour at the given locality.

On March 13, 1891, Mr. T. H. Thomas, R.C.A., and I measured the velocity of the bore between a point on the right bank of the river near the King's Head Inn (which is sixty yards north of the sixth milestone from Gloucester on the high road to Newnham) and a point further up on the right bank of the river, near Denny Farm and opposite to the fifth milestone from Gloucester.

The second hands of two watches were timed exactly together, and we found that the bore reached the first observer at ioh. $24 \mathrm{~m}$. $45 \mathrm{~s}$., a.m., and the second at $10 \mathrm{~h} .27 \mathrm{~m}$. $48 \mathrm{~s}$., a.m., the interval being 183 seconds.

Measured on the six-inch ordnance map, the distance along the central line of the river is 4750 feet. The velocity was therefore $17 \frac{7}{10}$ miles an hour for the part of the river observed. The river channel there is of a fairly uniform width of 250 feet.

The date chosen was that of the second highest tide of the spring equinox. At $10 h .25 \mathrm{~m}$. the height of the bore, above low water level, as measured by a post close to the river bank near the King's Head Inn, was $4 \mathrm{ft}$. roin. As the bore passed on, the level sank to $3 \mathrm{ft}$. $4 \mathrm{in}$. By Ioh. $3 \mathrm{Om}$. the water following the bore reached a height of $5 \mathrm{ft}$. $4 \mathrm{in}$. At Ioh. $32 \frac{1}{2} \mathrm{~m}$. the height was $6 \mathrm{ft}$. $4 \mathrm{in}$., and at Ioh. $34 \mathrm{~m}$. the water covered the post, the top of which was nearly $7 \mathrm{ft}$. above low water level. There was thus a rapid rise of the river in the rear of the bore. As seen in mid-stream, the height of the crest of the bore seemed only about $3 \mathrm{ft}$. above that of the water in front of it.

There was a gentle breeze from the north-east. Had there been a south-westerly gale blowing up stream, no doubt the phenomenon wou'd have been much more impressive, but it is of interest to record observations made under fairly normal conditions.

The rushing sound, heralding the advancing wall of water, was audible for some distance. The crest of the bore was whitened by a fringe of foam, and a good deal of spray was thrown up on the banks, where the water of the wave appeared to be higher than, and somewhat in advance of, that in the middle of the river.

A small boat in the path of the bore suffered no inconvenience beyond a slight tossing. The late Frank Buckland greatly exaggerated when he described the bore as "the greatest natural phenomenon in the British Isles," and stated that its pace was equal to that of an express train. Dr. Cornish (NATURE, vol. lxii. p. I27) estimates the velocity of the bore, on April 30, 1900, as eight miles an hour between Newnham Ferry and Denny Farm, a river distance of about nine miles. But the velocity evidently increases as the stream narrows, and, in the short portion which we observed, it will be noticed that the velocity was more than twice that estimated over the longer distance.

Leeds, February 3.

Chas. T. Whitmell.

\section{Persistence of the Direction of Hair in Man.}

IN "The Descent of Man," p. I9, under the heading of Rudiments, Darwin refers to the long isolated hairs seen in the eyebrows of certain individuals, as representing similar hairs in the superciliary region of the chimpanzee, baboon and certain species of macacus. An analogous phenomenon, with a different significance, found sometimes in the pectoral region in man, seems to be worth notice. I have recently examined two persons, a male aged twenty-eight and a female aged thirty-three years, both with particularly hairless, smooth skins, and each showing, at a critical point in the pectoral region, certain out. standing hairs set closely together, the former three long hairs an inch in length, and the latter two hairs an inch and a half in length. The point of interest lies in the position and direction of these few scattered hairs, which are as noteworthy, in their way, as "erratic blocks" on a level plain. In the female case the two hairs were set just over the middle of the left second costal cartilage, and they pointed persistently upwards towards the neck. In the male case the three long hairs were set close to the sternum in the left second intercostal space pointing persistently downwards. The situations of these two curious islets of hair are exactly above, on the one hand, and below; on the other, the level at which the upward chest-stream and the downward chest-stream always divide in a hairy subject. The remarkable persistence in their ancestral direction of these few "fossil" hairs, as they might be called, seems to confirm the view that if man has inherited his hairy covering from a simian ancestry it has been modified in many regions by use and habit since he inherited it. We say that a little straw shows the way in which the wind blows, and I submit that sundry stray hairs on the body of man similarly testify as to the trend of certain mechanical forces which have acted and still act upon him.

WALTER KIDD.

\section{The Colours of Wings of Butterflies.}

Mr. CROF''s letter (NATURE, January 2, p. I98) on the subject of colours of wings of butterflies raises an interesting point.

In pressing the wings of butterflies between sheets of gummed paper in order to obtain impressions for record, I have frequently noticed that in those cases where a brilliant light blue wing is to be pressed the impression usually fails to give the correct colour ; in transmitted light the impression is not blue, and in reflected light the colour is patchy and of a much darker blue; for example, the blue of a Junonia erithyia.

I have before me a wing-inside brilliant peacock blue, purple-blue, bronze-brown, according to the incidence of the light ; in transmitted light the colour is brown. The outside of the wing is brown.

Taking an impression of this wing in transmitted light the impression is brown, in incident light very dark blue and dark bronze in patches; the peacock blue fails entirely.

If a scale of this wing be examined under a low power it appears brown in transmitted light, but peacock blue (and varying shades according to position of scale on stage with reference to light) it the transmitted light be cut off and reflected light alone used.

It would appear, therefore, that this wing owed its chief colours to other causes than pigment. $\quad$ W. G. B. India, January 21.

\section{EXPERIMENTS ON VENTILATING COWLS.}

THE report of the work of the cowl committee of the Sanitary Institute presents the results of the numerous experiments made by the committee in the course of upwards of twenty years of its existence-an existence unfortunately terminated by the deaths in rapid succession of all its members. The last survivor, $\mathrm{Mr}$. Rogers Field, B.A., M.Inst.C.E, the most active member of the Committee, died on March 28, I900.

The committee left in manuscript more or less complete records of some seven thousand experiments on cowls and terminals, together with particulars of the arrangements for testing the instruments employed, a synopsis prepared with a view to a comprehensive report, and The Work of the Cowl Committee of the Sanitary Institute. Journal of the Sanitary Institute: (Edward Stanford, rgor.) 
some materials for a historical introduction, but practically no actual text. The council of the Sanitary Institute did me the honour of asking me to undertake the preparation of the report. For obvious reasons, the part that I could take in such an enterprise could only be a small one ; it was limited to supervising the work done by two of Mr. Rogers- Field's assistants and writing an occasional general note. In doing so I have regarded the report as addressed to those interested in the scientific study of pneumatics, and have not hesitated to call attention to the points in which the action of the com. mittee seemed to me to have missed the true scientific bearings of its work. I propose to be equally frank in what I have now to say, but I would not thereby be understood as decrying the accuracy or the value of the experiments. The study of pneumatics bas remained undeveloped probably more on account of the lack of accurate experiments and accurate measuring instruments than for any other reason. The records of the cowl committee bear ample testimony to the singleness of purpose of the committee in its desire to take all precautions and bring all conclusions to the test of accurate experiment, and the records of the experiments, with the limits of accuracy clearly apparent, must always be regarded as valuable data by which to test theoretical conclusions and an honourable memorial of a worthy effort to enlarge our knowledge of a most intricate subject.

The object of the committee was to compare, by direct experiment, cowls of different type as agents for producing a flow of air when exposed to wind and for preventing downdraught. The procedure adopted was to have three long vertical tubes projecting from a weather-boarded hut, erected, by permission of the Kew Observatory committee, in the Old Deer Park at Richmond. Each tube had an air meter inserted in it to measure the flow of air ; the lower end was protected from draughts by a box with a silk gauze bottom; an anemometer gave the velocity of the wind, the direction of which was also recorded. The cowl was mounted on the middle of the three pipes, and the flow through that pipe was referred to the mean of the flow through the two external pipes. The tests of downdraught were of various descriptions that need not be referred to here.

With the comparison of cowls of recognised shapes there was associated an endeavour to ascertain the effect of different modifications of the orifice of a pipe, and for this purpose a number of such modifications were constructed, and examined. Such modifications, some of which were very elaborate, are called terminals.

The report is divided into six parts :-

Part i. consists of extracts from introductory papers prepared by various members of the committee or from the correspondence preserved by the committee.

Part ii. contains an account of the testing of the air meters, and will be found to give a considerable amount of information of very great practical utility concerning the action of those instruments.

Part iii. gives the results of Mr. Rogers Field's investigation of the action of the anemometers employed. The instruments principally considered are a Robinson anemometer of the standard Kew pattern and a miniature instrument of the same type with one-inch cups. The chapter does not add much to the solution of the general problem of determining true wind velocity from the reading of a Robinson instrument, but it does show what kind of difficulties a careful and conscientious experimenter is likely to meet with if he sets about using such an instrument for the determination of true wind velocity. It also shows by some very useful diagrams the relation between the wind velocity and the flow up a vertical open tube over the end of which the wind passes.

Part iv. gives an examination of the degree of accuracy with which the mean of the flow in two outside pipes can NO. 1685 , VOL. 65$]$ be regarded as equivalent to the flow up the middle pipe. In some ways the results of this section are the least interesting of the whole number, because the observed differences which the committee attemped to resolve must be regarded as due to local circumstances which would probably not be reproduced in a repetition of the experiments under somewhat different conditions; but they are an essential part of the work of the committee; they show the limits of accuracy of the measurements under the prescribed conditions. Probably an experimenter with long experience of a laboratory:might have been content to recognise after a few experiments a certain margin of experimental error as incidental to the method, and have left the cowl results with that margin of error, or have selected conditions which gave the least experimental differences; but the committee seemed unwilling to write off an experiment as subject to a certain margin of error until it had fully probed all the causes of error.

Part v. gives the results for terminals, as defined above. The results which can best be generalised are those which are represented in the report by what are known as "hill curves," by which are to be understood curves representing results obtained from a series of consecutive experiments upon terminals varying by the gradual extension of some particular dimension.

Part vi. gives the results for cowls.

A consideration of the whole report gives rise at once to curious reflections. If an apostle of higher education were looking for an example of the importance of recondite theoretical study to matters of practice, of the necessity to practical life for the academic professor in any subject, not as an exponent of the facts of the subject, but as a student and investigator of its abstract laws, he could not wish for a better example than that furnished by this report.

The original committee was appointed to settle an apparently simple practical matter, namely, which was the best among a number of cowls exhibited at Leamington in 1876 in competition for a prize or certificate. The matter was apparently confined to the region of practice, and it was at first assumed that only a few experiments were needed to settle the points in question. Experiments were made, and the committee reported to the effect that no cowl at all was as good as any; and the award went in consequence to no cowl at all. But this did not by any means satisfy all concerned, and numerous complaints were made as to the experiments and the way of conducting them.

Thereupon the Sanitary Institute appointed Sir Douglas Galton, Mr. Rogers Field and Mr. W. Eassie-the lastmentioned was subsequently succeeded by Mr. J. Wallace Peggs - to be a committee to conduct further experiments. They set out to repeat the experiments with such precautions that their results should be accepted as final. They worked with unremitting labour and at no small expense ; tested to the uttermost every instrument employed in the investigation, and analysed all the conditions that might affect the results. They acted throughout upon the apparently simple practical principle that they could find out which was the best cowl if they could find out, for a certain strength of wind, which carried most air up a three-inch or a six-inch pipe, and up to what angle of tilt it could be set in various circumstances without suffering downdraught.

It certainly cannot be regarded as a fault in the committee that the subject had not been effectively worked at by some academic professor or student of experimental philosophy curious to learn, not which cowl should have a prize, but the general laws of flow of air through any cowl. They were capable, practical men, and naturally attempted a direct experimental answer. It may be true that in nine cases out of ten the best way of getting a practical answer to a scientific question is to set practical men to find it, 
and that a professor of natural philosophy would spend a long time over the inquiry and return an unpractical answer. The problem attacked by the cowl committee happened to be the exceptional tenth case in which, not academic students, but practical men, spent twenty years, a period, indeed, terminated only by the deaths of the members of the committee, without arriving at practical results of the final character looked for.

As a matter of fact, the flow of air along a three-inch or six-inch tube surmounted by a cowl is a very complicated result ; it is no more and no less the measure of the efficiency of the cowl on the top of the pipe than the current through a galvanometer is a measure of the efficiency of a battery cell in circuit with it. If we picture to ourselves a committee endeavouring to pronounce upon the relative merits of the battery cells of many inventors by tabulating the deflections which they produce in a galvanometer before G. S. Ohm had been led, by purely scientific researches, to the law which has been the guide in all such questions since his time, we get an exact analogy of the action of the cowl committee. Before the efficiency of the best cowl can be effectively represented by a number, it is desirable to settle what purpose the instrument is intended to serve. The production of a flow of air in a particular combination of tubes is doubtless one purpose, but there are others. Some cowls are intended to keep the rain out of a shaft; some are picturesque terminations of flues, as the Italian examples cited by $\mathrm{Mr}$. Ackermann in the cowl report; all, presumably, are intended to bring profit to their makers. As regards efficiency, they might be classified according to their performance with regard to one or other of these widely different purposes, but the classification would not be strictly scientific.

To the student of theoretical science they can only be regarded as examples of apparatus for diverting the kinetic energy of the passing air to produce a flow along the pipe which the cowl surmounts, whether the flow be up or down ; and the laws of transformation of the energy will most effectively describe the behaviour of the cowls from the scientific point of view. The flow along the pipe implies a certain expenditure of energy which must ultimately be derived from the passing air (in the absence of temperature difference), and the primary effect of the cowl may be estimated by the amount of energy which it takes from the wind and diverts to producing or maintaining a flow. We may call this the aëromotive force on the analogy of an electromotive force of a battery maintaining an electric flow in a circuit.

This conversion of the energy of wind into aëromotive force is in itself a very interesting subject. There is no doubt that by suitable mechanism of the windmill type (hinted at by the Archimedean screws of some revolving cowls) the wind could be made to lift through a chimney, not only air, but also, if desired, the cinders or the coals, and even the firegrate and the hearthstone itself; but the limits of effectiveness of purely pneumatic as distinguished from mechanical arrangements would be a very useful and productive subject for study. To take the matter a stage further in detail and ask whether it is possible by any combination of plane or curved surfaces to make the velocity of the air passing over the mouth of a tube greater than the original velocity of the wind, is to suggest an inquiry with important bearings upon many scientific subjects. For example, when wind blows through a truncated cone along the axis of the cone, is the velocity of emergence greater than the velocity of the unimpeded air? The cowl results do not answer this question, but indicate some suggestions. They show that a large cowl is more effective than a smaller one of similar pattern upon the same pipe ; that the output of a pipe can be considerably increased by surmounting it with an extending cone-piece and adding at the widened end a "louvre" band attached NO. I 685 , VOL. 65$]$ by a regulated number of "feathers," and above that a cap at a certain distance. Whether this arrangement actually increases the velocity of the air passing over the mouth of a tube or merely prevents diminution only a master of theory can say. There is no experimental answer to this question.

Just as the current in a galvanometer gives no final indication of the electromotive force of a battery in its circuit, so the air current in the tube gives no final indication of the aerromotive force of the cowl. The resistances of all parts of the circuit and any accessory aëromotive forces must likewise be accounted for.

The resistances to be accounted for must refer to all parts of the complete circuit and are more complicated than electrical resistance, for they depend partly upon friction in which the loss of energy is proportional to the first power of the velocity and partly upon the turbulent motion in which the loss of energy is proportional to the square of the velocity. Thers are also in the -circuit of flow arranged in the cowl experiments other aëromotive forces than that due to the cowl. In order to make this clear, it is sufficient to point out that the circuit consisted of the cowl, a length of three-inch pipe, an air meter, a short pipe opening into a box with a silk gauze base, and some opening, either door, or window, or chinks, between the interior of the hut where the observer was accommodated and the outside air. If the cowl had been removed the flow would not have ceased; even if the long tube were removed altogether there would be some flow through the opening, and if the opening were in the side of the hut instead of the top there would still be flow, thus indicating aëromotive forces quite apart from that due to air passing over the cowl or the top of the open tube.

The cowl committee made no inquiry into the different elements which go to make up the composite effect read on the air meter, and consequently made no attempt to analyse the effect of a cowl into the production of aerromotive force and resistance, just as the effect of a battery nay be analysed into the production of electromotive force and electrical resistance. As downdraught is reversed flow, the same kind of uncertainty attaches to the results of the committee's experiments upon this branch of the subject.

The most confusing results are those for cowls used as injectors. In the case of exhaust cowls, comparison was made between the flow in three parallel pipes, the middle one carrying the cowl, the other two bare. The direction of the flow was the same in all three and all were fed from the interior of the same hut. When the effect of an injector was to be measured it was mounted upon the middle pipe, the outside pipes still remaining free. The aëromotive force in the injector pipe was, of course, reversed; one pipe supplied air to the hut and two extracted air from it. In that case flow could go on if the hut were otherwise hermetically sealed, and allowing for the hut being leaky, as it was, intentionally so, the network of currents is so complicated that it is difficult to attribute any precise meaning to the relation of the flow down the middle pipe and to that up the outside pipes, the relation selected by the committee to represent the effectiveness of the injector.

I have given some justification of the statement that the results obtained by the committee are no more indicative of the characteristic action of cowls than galvanometer readings are of the characteristics of batteries; I should like to add some words in explanation of the parallel statement that they are no less so.

If the resistances in an electric circuit are all maintained the same and the only changes introduced are successive slight modifications of the battery itself, it is quite possible to obtain from the corresponding galvanometer readings sufficiently definite information about the effect of the changes in the battery. Examples analogous to this are afforded in the report by numerous comparisons of 
the effect of the different aspects of what may be called polarised cowls or terminals, i.e. cowls or terminals the action of which is different according to their position with regard to the direction of the wind. One of the most conspicuous is that of a cowl of the same shape as the torpedo air extractor now so much in use on railway carriages. From the numbers given, the apparatus is clearly much more effective when the wind crosses the opposed cones than when it passes along the cones and through the ring, and this difference of action is definitely characteristic of the two positions of the cowl.

Towards the end of the period of its labours the committee began to approach the question in more academic or philosophical fashion. Experiments with smoke were tried to see how cowls and terminals really acted. The committee was thus led to test the effect of successive variations of the number, size, position and arrangement of different modifying elements, such as a flange at the rim of the orifice or at a measured distance from it, a set of "feathers" arranged round the orifice and "louvre" bands or caps above it. A series of experiments to test the effect of the variation of a single element was carried out on single days and the results plotted in curves for the single varying elements. Here we have as results only galvanometer readings for different batteries, so to speak, but for batteries varying only in a single particular, and from such information effective inferences can be drawn about the action of the battery. These results afford the best material in the report for the scientific study of the action of cowls. It still remains only material, and requires working up with due regard to the theoretical considerations referred to. But some practical results follow directly. For example, a flange surrounding the orifice of the pipe diminishes the aëromotive force produced by wind passing over it, and if sufficiently extended practically an$\mathrm{n}$ :hilates the flow. It is nnt by any means impossible that an examination of these curves may lead to further investigation of the laws of flow through tubes under the action of passing wind. It is a subject which presents all the difficulties of the corresponding electrical problems, with some added in consequence of the inertia of the moving fluid, but it is of great practical as well as theoretical importance, and the report will have done good service if it attracts attention to the further study of the subject from this aspect.

One of the most amazing facts about the history of science in the last century is the little progress made in our knowledge of pneumatics compared with the advances in our knowledge of the flow of electricity, which still borrows its language for practical purposes from the older and now almost neglected study of the flow of fluids. The theoretical development of electricity can be attributed to Faraday's experimental investigation of the laws of electromagnetic induction. The flow of air along pipes in consequence of wind passing over the top may fairly be regarded as a case of pneumatic induction. The experiments of the cowl committee, if they have not succeeded in classifying these inductive effects into laws, have reopened the study of the subject, and at least give evidence that it is not the fulness of experimental knowledge that has dissuaded the intellects of the students of our laboratories from its investigation.

W. N. SHAW.

\section{GOLD IN INDIA.}

NDIAN gold is attracting the attention of the Geological Survey of India. In NATURE for May 9, I9OI we directed attention to Dr. F. H. Hatch's report on the Kolar gold-field in Mysore. We have now received reports on the gold-fields of Wainád, by Mr. H. H. Hayden and Dr. Hatch, and on some auriferous localities in north Coimbatore, by Mr. Hayden (Mem. Geol. No. I 685 , VOL. 65$]$
Survey, India, vol. xxxiii. part ii. 190r.) These districts lie to the south of Mysore. The extraordinary discrepancy between reports made on various properties of Wainád by mining experts and the actual results subsequently obtained have justified independent investigations on the part of the Indian Government. It is recorded that in I880 numerous companies, having an aggregate capital of more than four million pounds, were floated on the London market; of these only three companies retain their properties, and no work has been done for a number of years. The question to be solved was whether improved modern methods might render it possible to revive the gold-mining industry in the area. Dr. Hatch's report is, however, unfavourable. Dealing specially with two mines, he finds that ore does not occur in payable quantity, and he is unable to recommend further prospecting. Mr. Hayden gives an interesting historical sketch of the gold-mines, and describes in some detail the geological features of the district. The country-rock is in most cases biotite gneiss; this has been affected by a series of parallel fissures which run obliquely to the direction of the foliation, and in these fissures the vein-material was deposited. : Pyrites proved to be the chief source of the gold, but the richer orebodies are small irregular patches, not of sufficient extent to be of material value.

$\mathrm{Mr}$. Hayden remarks that there are few auriferous areas in India, poor as well as rich, that have not at some period or other been exploited by the natives; but the fact that gold was obtained in sufficient quantity to cover the expenses and leave a margin of profit, does not in itself justify the belief that a good margin of profit would be obtained if modern methods of working were adopted. Many of the reefs were probably mined by forced labour or by slaves. Thus one of the Wainád reefs, which was, perhaps, worked more extensively than any other, has given, from nearly 200 samples, an average yield of about two pennyweights of gold to the ton of ore. In Coimbatore there are numerous old native workings for gold, but they are, as a rule, small and unimportant, and the ore-bodies are either very thin or barren. Further prospecting, however, appears to be advisable in this district.

\section{NOTES.}

THE attendance of the Prince of Wales at the meeting of the Royal Society on Thursday last is an event which we have pleasure in recording. His Royal Highness was formally admitted as a Fellow of the Society, and remained throughout the meeting. At the close of the proceedings he was invited by the president to address the meeting, and in response he said :"Mr. President, my lords and gentlemen,-It gives me very great pleasure to have been able to come here to-day and to be formally admitted as a Fellow of this ancient and distinguished society. But, as you conferred the honour of Fellowship upon me some eight years ago, I really ought to apologise for not having presented myself before. I can only say I am indeed proud that my name should be added to those on your illustrious. roll, which has been inscribed by nearly every Sovereign since the reign of Charles II., and by all the most distinguished men of science since those days, such as Wren, Newton, Davy, Faraday, Darwin, and many others. I would wish to offer my sincere thanks to Sir William Crookes for his most interesting lecture, which I am sure we have all listened to with great pleasure. If I may be allowed to do so, I should like to con. gratulate him on his power of treating such an abstruse question (for I must confess that the title rather alarmed me) so as to make it intelligible and attractive to those who, like myself, unfortunately cannot lay claim to much scientific knowledge. But, while fully, realising how far beyond my reach this 